\title{
Model, Theory and Evidence in the Discovery of the DNA Structure ${ }^{\dagger}$
}

\author{
Samuel Schindler ${ }^{\ddagger}$ \\ UNDER REVIEW \\ PLEASE DO NOT CITE WITHOUT PERMISSION
}

\begin{abstract}
In this paper I discuss the discovery of the DNA structure by Francis Crick and James Watson, which has provoked a large historical literature but has yet not found entry into philosophical debates. I want to redress this imbalance. In contrast to the historical literature a strong emphasis will be placed upon analysing the roles played by theory, model and evidence and the relationship between them. In particular, I am going to discuss not only Crick and Watson's well-known model and Franklin's x-ray diffraction pictures (the evidence) but also the less well-known theory of helical diffraction, which was absolutely crucial to Crick and Watson's discovery. The insights into this ground-breaking historical episode will have consequences for the "new" received view of scientific models and their function and relationship to theory and world. The received view, dominated by works by Nancy Cartwright and Morgan and Morrison (1999), rather than trying to put forth a "theory of models", is interested in questions to do with (i) the function of models in scientific practice and (ii) the construction of models. In regard to (i), the received view locates the model (as an idealized, simplified version of the real system under investigation) between theory and the world and sees the model as allowing the application of the former to the latter. As to (ii) Cartwright has argued for a phenomenologically-driven view and Morgan and Morrison (1999) for the "autonomy" of models in the construction process: models are neither determined by theory nor by the world. The present case study of the discovery of the DNA structure strongly challenges both (i) and (ii). In contrast to claim (i) of the received view, it was not Crick and Watson's model but rather the helical diffraction theory, which served a mediating purpose between the model and the x-ray diffraction pictures. In particular Cartwright's take on (ii) is refuted by comparing Franklin's bottom-up approach with Crick and Watson's top-down approach in constructing the model. The former led to difficulties, which only a strong confidence in the structure incorporated in the model could circumvent.
\end{abstract}

Keywords: DNA structure, model-building, phenomenologically-driven view, models as mediators, Inference to the Best Explanation.

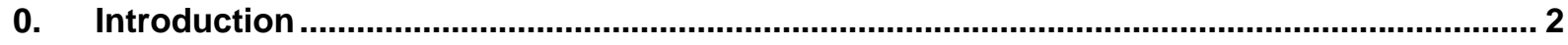

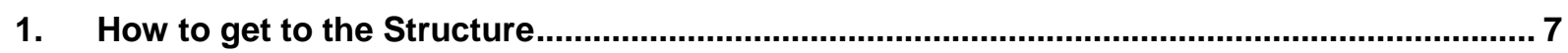

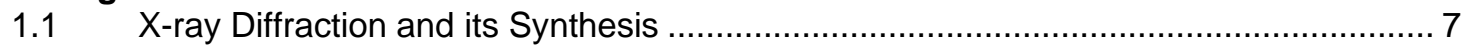

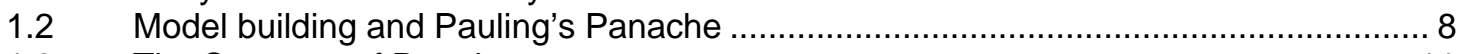

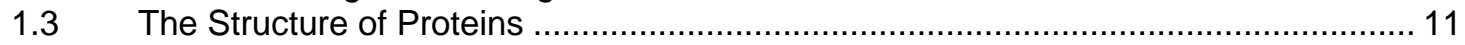

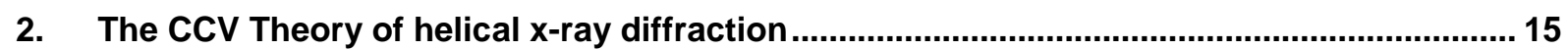

$2.1 \quad$ The role of the CCV theory in the discovery of the DNA structure .............................. 17

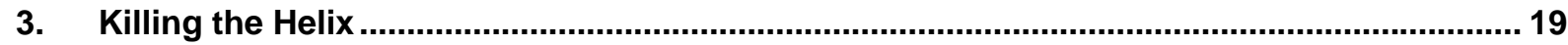

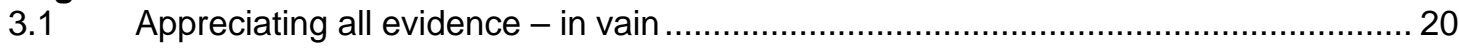

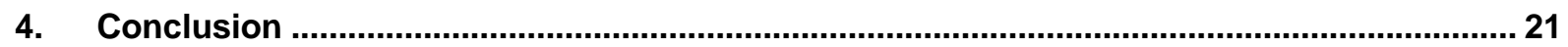

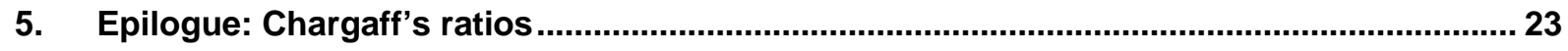

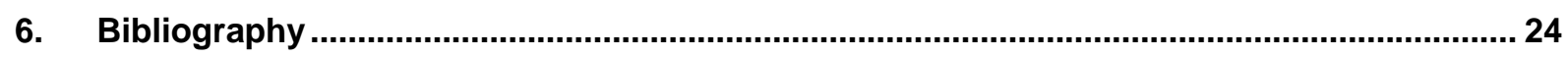

\footnotetext{
${ }^{\dagger}$ I wish to dedicate this paper to the superior theoretician Francis Crick (1916-2004).

* School of Philosophy, Division of History and Philosophy of Science, University of Leeds, Woodhouse Lane, Leeds, LS2 9JT, UK, s.schindler04@leeds.ac.uk.
} 
It is also a good rule not to put too much confidence in the observational results that are put forward until they are confirmed by theory.

(Sir Arthur Eddington 1934, New Pathways in Science, 211)

\section{INTRODUCTION}

The discovery of the DNA structure has been the subject of two big historical volumes (Olby 1994, Judson 1996), numerous memoirs, biographies and anniversary articles ${ }^{1}$. One might say that not many episodes in the history of science have been covered as well as this discovery. Thus,

[i]t appears that everything that could be said about [the discovery of the DNA] has been said, that there is no unknown element that could falsify this or that aspect of the story, or at the very least provide a new an original point of view. (Morange 1998, 111)

In spite of the rich resources provided by the historians, rather oddly, the discovery of DNA has not found entry into philosophical debates. It is the aim of this paper to remove this "blind spot" of the philosophy of science by making available well-chosen aspects of the history and presenting them in a form, which offers more appeal to the theoretically interested reader than mere historical narratives and descriptions, which are at best entertaining but contain rather little insight.

On the very few occasions philosophers of science do refer to the discovery of the DNA structure their analysis concentrates on the physical nature and the representive function of the model Crick and Watson constructed of the DNA structure ${ }^{2}$. I, however, regard the physical nature of the model peripheral and rather untelling in philosophical terms ${ }^{3}$. Instead, in this essay I am going to discuss Crick and Watson's DNA model in terms of contemporary accounts of the relationship between the model, theory and the world.

In recent discussions about models the focus has shifted away from early attempts to characterize and classify models with a strong emphasis on metaphors and analogies (Black 1962, Hesse 1966, Achinstein 1968) and later efforts to define scientific models formally (Suppes 1960, van Fraassen 1980) towards (i) the function models fulfil in scientific practice and (ii) how they are constructed ${ }^{4}$. Considerable responsibility for having brought about the latter shift belongs to Cartwright (1983), Cartwright et al. (1995) and Morgan and Morrison

\footnotetext{
1 Franklin has been portrayed by Sayre (1975) and Maddox (2002). Of course, some biographies and memoirs are less valuable than others. Sayre's book is a rather angry attempt to defend Franklin against an apparently women-hostile, male-dominated science and not very valuable for the purposes of my paper. The highly praised memoir by Watson in my opinion, too, belongs into the less valuable category. Although Crick's furious assessment of Watson's memoir after his first reading is harsh I do feel sympathetic to it: "Should you persist in regarding your book as history I should add that it shows such a naïve and egoistical view of the subject as to be scarcely credible. Anything with any intellectual content, including matters which were of central importance to us at the time, is skipped over or omitted. Your view of history is that found in the lower class of women's magazines." (Crick in Judson 1996, 157) I certainly think it is a gross misunderstanding to interpret Watson's memoir "as it really was" (Merton 1968; in Watson 1980, 213).

${ }^{2}$ See, for instance, Giere (2002) and Frigg and Hartmann (2006). Usually, the philosophers' analysis does not go beyond merely mentioning the physical character of Crick and Watson's model.

3 That the physical nature of Crick and Watson's model cannot be as important as philosophers of science have believed (without having even attempted to gain a deeper understanding of the model) is apparent from the fact that nowadays the same task is done exclusively with computer models.

${ }^{4}$ See Schindler (2006) for a contrast between the formalist and the "methodological" approach for describing the semantic view and Cartwright's and Morgan and Morrison's view on models respectively. See also BailerJones (1999) for a rather biased narrative on the development of the philosophical treatment of scientific models.
} 
(1999). These philosophers of science, to a large extent, have given up finding a proper definition of scientific models:

Although we want to argue for some general claims about models - their autonomy and role as mediating instruments, we do not see ourselves as providing a 'theory' of models. The latter would provide well-defined criteria for identifying something as a model [...]. (Morgan and Morrison 1999, 12)

Although one is confronted with the reluctance to define models and with a particular reluctance to define models in formal terms (as the proponents of the semantic view prefer to), often it is implicitly assumed that models are "simplifications", "idealizations", or "distortions" of the real system, which is clear from the following quote by Cartwright:

I think that a model - a specially prepared, usually fictional description of the [real] system under study - is employed whenever a mathematical theory is applied to reality and I use the word 'model' deliberately to suggest the failure of exact correspondence [with reality] which simulacra [i.e. models] share with both Hesse's analogical models and with Redhead and Cushing's theoretical models (Cartwright 1983, 158p.)

That is, for Cartwright a model is a fictitious entity (she also refers to it as "simulacrum", or the "prepared description"), which distorts reality in order to allow the application of the theory to reality. The theory is only true of the objects in the model, not of real ones (ibid., 17). In other words, the model renders reality palatable to the theory, although the model itself is constructed without the use of theory:

[W] present the phenomenon in a way that will bring it into the theory. The most apparent need is to write down a description to which the theory matches an equation [...] This first stage of theory entry is informal. There may be better and worse attempts, and a good deal of practical wisdom helps, but no principles of the theory tell us how we are to prepare the description. (Cartwright 1983, 133p.; my italics)

More recently, Cartwright, with others, (Cartwright et al. 1995) has emphasised precisely this "bottom-up" construction of models independently of theory"

What is needed is the recognition of the independence from theory, in methods and aims, of the scientific activity we have come to call phenomenological model building. (Cartwright et al. 1995, 148) Instead of a theory-driven view of models, we suggest a phenomenologically-driven one. (ibid., 137)

However Cartwright et al.'s blunt claim that model building proceeds independently of theory "in methods and aims" is slightly weakened by Cartwright et al. in the same paper where they concede that "[t]heory plays its own small important role [in the construction of models]. But it is a tool like any other; and you can not build a house with a hammer alone." (140) Still, Cartwright utterly rejects deduction from theory to models as playing any part in this construction process:

Another kind of argument depends on looking at how we arrive at models in physics - not by deduction from basic theory it turns out. (140)

The same goes for the relation between theory and reality.

But treatments of real systems are not deductive; nor are they approximately deductive, nor deductive with correction, nor plausibly approaching closer to deductivity as our theories progress. (Cartwright 1999a, 9)

\footnotetext{
${ }^{5}$ French and Ladyman (1997) have criticised this view by reconsidering Cartwright et al.'s case study of London and London's model of superconductivity in pitiless detail and came to the conclusion that Cartwright et al.'s analysis of the case was rather superficial and does not support their conclusions - in particular in regard to phenomenological model building.
} 
Thus in conclusion, according to Cartwright, models are fictitious entities, which allow the application of the theory to the world (their function) and they are built from the bottom-up from the phenomena without the use of any deductions from theory (their construction). Let us now consider the "models as mediators" view as characterized by Suarez in Models as Mediators edited by Morgan and Morrison (1999):

Mediating models always stand between theory and the physical world. Their main function is to enable us to apply scientific theory to natural phenomena [...] Morrison has identified three main features. First mediating models are not derivable from theory [...] Secondly, these models are not necessitated by the empirical data either [...] Finally mediating models have a very significant property: they can replace the physical systems as the central objects of scientific inquiry. (Suarez 1999, 168)

Again, like Cartwright, the proponents of the "models as mediators view" claim, and emphasise more strongly than Cartwright, that the model allows the application of the theory to the world. The model is explicitly located "between" theory and the world. However, as regards the construction of the model, it is neither determined by theory ("top-down") nor by data ("bottom-up"). The model is "autonomous". At this instance it is interesting to note that also the semantic view (the predominant formalist account of models), which often serves as the target of attack for Cartwright and Morgan and Morrison, not only locates the model between theory and the world (see Giere 1988, 83 for a pictorial illustration of this) but also allocates the same function to models as Cartwright and Morgan and Morrison. According to Morrison "[...] the semantic view suggests that we need models where we want to fit the theory to concrete situations" $(1999,42)^{6}$.

In this essay I shall show that the discovery of the DNA structure challenges the received view of models in regard to the nature and the construction of models and in regard to the function they fulfil. First, I want to question the appropriateness of the theory - model world trichotomy and the model's function of allowing the application of theory to the world, about which philosophers of science do not seem to have any disagreement. It will be shown that the discovery of the DNA saw the theory "mediating" between the model and the world. It must be stressed that this is different from Weisberg's very recent account of Abstract Direct Representation (ADR) (Weisberg forthcoming) ${ }^{7}$. ADR, according to Weisberg, is the representation of phenomena "without the mediation of a model" (ibid., 4). Although this seems to be one of the claims I will argue for in this paper, Weisberg's claim is different from mine. Before we can see why this is so, we have to understand how Weisberg differentiates between "modelling" and ADR.

... the most distinctive characteristic of the practice of modeling is the analysis of a real world phenomenon by first analyzing a model. Hence the process of representing a model becomes the first step in representing a real world phenomenon. This is distinct from ADR because, in ADR, there is no intermediary stage. Theorists engaged in ADR analyze and represent the properties of a real world phenomenon, suitably abstracted, in the first instance. Their aim is to represent a real phenomenon and analyze their representation of this phenomenon. (ibid., 17)

\footnotetext{
${ }^{6}$ Patrick Suppes, one of the founders of the semantic view, conjectured that there were many different sorts of models: data models, models of phenomena and theoretical models. However the fact remains that he too located those models between the theory and the world.

${ }^{7}$ Godfrey-Smith (2006) not only draws on Weisberg but seems to have been involved in developing ADR. I would like to thank one of the referee's of this paper for drawing my attention to Weisberg's and GodfreySmith's accounts.
} 
Whereas in modelling one "starts with" the model (by abstracting and idealizing from the phenomena), analyses this model and then "coordinates the model with the phenomena", in ADR one abstracts from the phenomena in order to construct a "representation" of the real phenomena, without first constructing an idealization or simplification of the real phenomenon. Whereas modelling, according to Weisberg, is an indirect form of theorizing, ADR is a direct form. There are many problems with Weisberg's account. First of all, it does not seem to be entirely clear, if there is really any difference between a model and a representation in ADR. Both, Weisberg admits, are abstractions of the real phenomena. If there is no difference between the two, modelling and ADR collapse into one account ${ }^{9}$. More importantly, it is not immediately clear what the difference is supposed to be between ADR and classical hypothesis construction. Confronted with a phenomenon, one constructs a hypothesis, which is to explain the phenomena in question, of course, without the mediation of a model. ${ }^{10}$ But all these difficulties aside, I'm making a very different claim from Weisberg. I am not saying that there was no model involved in the discovery of the DNA structure - which would be foolish anyway - but rather that the order of the standard theorymodel-evidence trichotomy has to be altered in order to account for the historical episode in question.

The second challenge I want to put forth against the received view of models concerns the construction and the nature of models as idealizations or simplifications of the real system under consideration. It is hard to see in what sense Crick and Watson's model is to be considered a simplification or idealization of the real structure of DNA. After all, before Crick and Watson discovered the structure of DNA, no one knew how the real structure looked like. So how could they have possibly simplified this real structure in a model $?^{11}$ Now, one might want to say instead that the DNA structure was inferred from the evidence. The only inference from the evidence towards a hypothesis philosophers of science have come up with hitherto is the inference to the best explanation (IBE). IBE usually is held by scientific realists but rejected by anti-realists, most notably by Bas van Fraassen. IBE is the claim that the scientist starts with a set of data and from them infers the truth of the hypothesis which can account for the data best:

In making this inference one infers, from the fact that a certain hypothesis would explain the evidence, to the truth of that hypothesis. In general, there will be several hypotheses which might explain the evidence, so one must be able to reject all such alternative hypotheses before one is warranted in making the inference. (Harman $1965,89)$

Okasha (2000) has pointed out that although van Fraassen has attacked IBE on the basis of the assumption that IBE is meant to operate in the context of justification, IBE actually is meant to be applicable to the context of discovery too. That is, rather than being used as just some sort of selection procedure for choosing between various hypotheses already in place given a particular set of evidence, IBE also is to be taken as a method for generating hypotheses, which can then be compared and selected for the best:

\footnotetext{
${ }^{8}$ Weisberg is very obscure on what he calls the "coordination with phenomena". He merely alludes to some form of Giereian similarity relationship between the model and the world, but does not even say how this is supposed to be achieved.

9 Weisberg does reserve idealizations to model building, however, he is not clear enough on for them to be a proper distinguishing feature idealizations (he only says that idealizations lower "one's standards of fidelity; Weisberg forthcoming, 25).

10 This seems to be particularly the case for the Darwin's "theory" of atoll formation, which is one of exactly two examples Weisberg quotes in support of his ADR account. The other example is Mendeleev's table, which many people would not even be happy to call a theory. This includes even Mendeleev himself: "I shall not form any hypotheses, either here or further on, to explain the nature of the periodic law". (Mendeleev, 1879, p. 292)

11 One might even want to say that it is the physical model which is to be considered as a simplification of the real structure. Yet, the irrelevance of the physical nature of Crick and Watson's model was pointed out above.
} 
Given a puzzling phenomenon, we construct a number of hypotheses to try to explain it, and choose the one we think explains the phenomenon best. Looked at this way, IBE is not simply a way of selecting between already existing hypotheses, as per van Fraassen, but also a way of generating the hypotheses on which the selection procedure operates. (Okasha 2000, 695)

The generation of hypotheses by Saunders Peirce was even characterised as the fundamental feature of abduction (the precursor of IBE) distinguishing it from deduction and induction:

Abduction is the process of forming an explanatory hypothesis. It is the only logical operation which introduces any new idea; for induction does nothing but determine a value [?], and deduction merely evolves the necessary consequences of a pure hypothesis. (Peirce $\mathrm{xxx}, 5.171$; my emphasis)

So, one needs not commit to scientific realism in order to be sympathetic to IBE as a form of discovery procedure. Therefore, although Cartwright has followed van Fraassen in rejecting IBE as an inference to the true explanation (see Cartwright 1983), I take it that she, through her phenomenologically-driven view on the construction of models, is committed to IBE as a construction procedure. Although Cartwright has remarked that she has "no quarrel with induction as a form of inference" (Cartwright 1999a, 12), induction is not the appropriate form of inference in the discovery of the DNA. In induction one reasons from particulars to universals. And yet, in the case of the superconductor, with which Cartwright et al. have developed their notion of the phenomenologically-driven view, as well as in the case of the discovery of the DNA structure, which is going to be discussed in this paper, induction does not seem to be the appropriate form of reasoning. Rather than generalizing over a large number of phenomena only very few phenomena (the Meissner effect in the case of superconductivity and particular x-ray patterns in the case of the discovery of the DNA structure) seem to be crucial for the construction of the respective models in two cases in question. That is, both the DNA model and the model of superconductivity are not the result of empirical generalizations but seem to be rather the result of very specific conjectures about a particular real system. And it was exactly this sort of inference which Rosalind Franklin was using in her attempt to reveal the structure of DNA. Franklin conducted experiments and on the basis of the obtained evidence she tried to infer the structure that would fit her data best. All the hypotheses she was considering, she subjected to the evidence and was happy to reject a hypothesis, if it did not "fit the data". Furthermore, the hypotheses she was taken into account had to fit all the data available. On the other hand, Crick and Watson chose a very different path. They did not start with the x-ray photographs, the only direct evidence of the structure available, but rather, as is well known, built models on the basis of the known bond angles and distances of the component parts of the DNA. In contrast to Franklin, who was considering every hypothesis she could think of, Crick and Watson stuck to one structural hypothesis throughout. There was not a single moment when they doubted that the DNA structure would be helical and did not allow any evidence to refute this hypothesis. They simply ignored the evidence, which others took as a straightforward refutation of the helical hypothesis. Crick and Watson did not construct their model from the bottom-up, as Cartwright et al. have claimed for the case of superconductivity (which they hold to be a most representative case). Rather, "top-down" deductions derived from a supposed helical structure - contrary to Cartwright's outright rejection of the importance of deductions in scientific practice (cf. p. 3) - played a most crucial part in the discovery of the DNA structure ${ }^{13}$. I consider Crick and Watson's approach, which led to the ultimate solution of the DNA structure, to be highly problematic in particular for Cartwright's phenomenologically-driven

\footnotetext{
12 For the same point see also Lipton $(2004,67)$.

${ }^{13}$ See also Schindler (2007) for the claim the phenomena of the zebra pattern that kicked off the plate tectonic revolution was constructed from "top-down" rather than from the "bottom-up".
} 
view and furthermore for those philosophers of science, who take abduction and IBE to be necessary and sufficient forms of discovery procedures.

In the first section of this paper I will introduce the two principal methods of how to get to the structure of macromolecules in general and the structure of DNA in particular. We shall see that Franklin used a rather "direct" method starting from the x-ray diffraction pictures, the only direct evidence of the macrostructure. The reader will be made briefly familiar with x-ray crystallography, the technique used to study the structure of crystals and crystallisable material like DNA. The other principal method of "how to get to the structure" involves model building. Hypothetical structures are sought to be assembled coherently from the smaller components of the macromolecule. This was the method used by Pauling, who was followed by Crick and Watson, who admired Pauling's "panache" in model building and despised Franklin's direct approach. We shall see that Pauling's reported panache in discovering the structure of proteins had to do with his preparedness to disregard x-ray diffraction evidence, which others took very seriously. In Section 2 we shall encounter the consequences, which were derived from Pauling's protein model, and among them, the consequences predicted by the helical diffraction theory, developed by Crick, Cochran and Vand $(\mathrm{CCV})$, which were to play a pivotal part in the discovery of the DNA structure. The role of the CCV theory, in particular, has been denied the attention it deserves. In Section 3 we shall consider the reasons why Franklin rejected the helical structure to be viable for the structure of DNA and how she was able to convince her colleagues Wilkins and Stokes of this. In Section 4 I will review the philosophical argument being made throughout this paper and the historical evidence presented in its support.

\section{How to get to the Structure}

At the time of the discovery of the structure of DNA (1950s) there were two distinct ways to get to the structure of macromolecules. One was to work out the structure from the only direct evidence of the macrostructure available, namely from x-ray diffraction pictures. The other method included model building, where the bond angles and distances of the smaller components of the macromolecule were tried to be fit into a coherent whole ${ }^{14}$. Whereas Franklin chose the former approach "from the bottom up", as it were, Crick and Watson chose the opposite approach from the top-down from the structure towards the evidence. Let me describe Franklin's method in the next section before going on to Crick and Watson's.

\subsection{X-RAY DifFRACTION AND ITS SYNTHESIS}

By means of $\mathrm{x}$-ray diffraction one can determine the positions of atoms in a crystal lattice ${ }^{15}$. The x-rays, whose wavelength is of the same order of magnitude as the spacing between the atoms in a molecule, are diffracted by the electrons and leave spots of varying intensity on a photographic plate. The photographs obtained from x-ray diffraction are not like ordinary photographs due to the impossibility of refracting $x$-rays. The information contained in the photograph gives only half of the information necessary for the knowledge of the structure of the investigated molecule: the intensities of the reflected ${ }^{16} \mathrm{x}$-rays but not their phases. Yet,

\footnotetext{
${ }^{14}$ Although other methods like ... have been added since, even nowadays X-ray diffraction and computer-aided model-building are the two main means of figuring out the structure of macromolecules.

15 "A lattice is a geometrical abstraction of the arrangement of any regularly repeating system, which could be a protein crystal, or wallpaper [...] The repeating section is known as the unit cell of the structure." (Holmes and Blow 1980, 124; italics added)

${ }^{16}$ Due to Bragg X-ray diffraction can be treated as reflection from parallel imaginary "mirror" planes in the molecule in the crystalline state. Only x-rays with certain angles of incident are reflected (determined by Bragg's law). Bragg's idea of the "mirror" planes and the law derived from this idea laid the basis for x-ray crystallography (cf. Cracknell 1969). With the help of the Bragg equation $n \lambda=2 \mathrm{~d} \sin (\theta)$ derivable from the
} 
both the amplitudes (calculated from the observed intensities) and the phases are necessary for
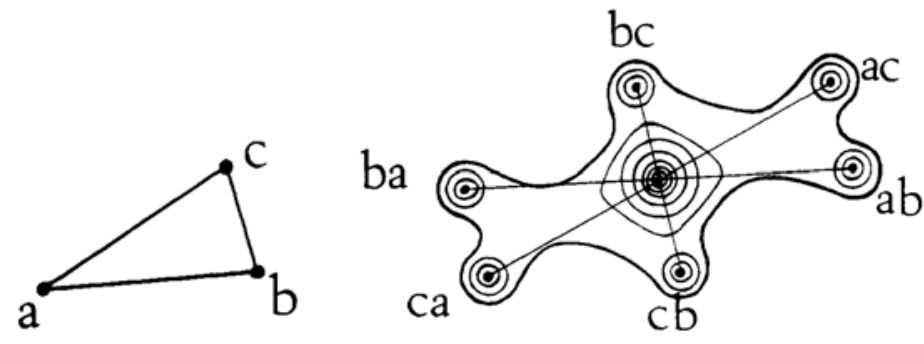

Fig. 1 Patterson map (right) of a simple triangular structure (left). The letter pairs in the Patterson map correspond to the respective interatomic distances in the original structure. Notice that, although the Patterson contains information about the interatomic distances, the positional information is entirely removed in the Patterson map: all vectors relate to the origin.

method or the method of isomorphous replacement ${ }^{18}$. Those methods, however, cannot be applied to long-chain polymers like the DNA (cf. Olby 1996, 38p). Nevertheless, one can circumvent the phase problem by using the so-called Patterson synthesis. The Patterson synthesis is a Fourier series with intensities instead of amplitudes as coefficients. Since the phases do not enter the Patterson synthesis so the Patterson map only shows the interatomic distances but not the absolute atomic positions (Fig. 1), which results in $N(N-1)$ peaks (not including the central peak and any overlap) relative to the peaks to be observed in a Fourier contour map ${ }^{19}$. It was the Patterson function with which Franklin tried to determine the structure of the DNA. Franklin's only collaborator at King's college, the PhD student Gosling, has expressed Franklin's attitude towards the structure of the DNA thus:

And I felt repeatedly that [Franklin's colleague at King's college] Maurice [Wilkins] was trying various ways to stimulate Rosalind into saying something about the structure, but she for her part would say, 'We are not going to speculate, we are going to wait, we are going to let the spots on this photograph [via the Patterson] tell us what the structure is.' (Gosling in Judson 1996, 127; italics added)

Crick and Watson were critical about Franklin's approach:

Pauling's paper [on the structure of proteins; see below] is at least in the proper mood and the type of approach which the people at Kings College London should be taking instead of being pure crystallographers. (Watson to Delbrück, 20 February 1953, in Judson 1996, 146) Everything she did was sound enough - almost too sound. She lacked Pauling's panache. (Crick 1989, 69)

\subsection{Model building and Pauling's Panache}

In 1950 Pauling, together with Robert Corey and Branson (henceforth PCB), discovered the structure of protein molecules ${ }^{20}$. However, Pauling did not use the method from the "bottom-

\footnotetext{
Bragg model one can calculate the interatomic distances, which used to be measured in Angstrom units (Á), whereby $1 \AA=10^{-1} \mathrm{~nm}$. Instead of Angstrom units nowadays nanometre is the standard unit. I shall stick to the Angstrom units throughout this essay for it used in the literature I'm referring to.

${ }^{17}$ Fourier series can represent "any physical event that repeats at regular intervals" and reduce it to a "set of simple wave forms, with equivalently simple mathematical statement" (Judson 1996, 516).

${ }^{18}$ Cf. Kendrew and Perutz (1949) and Crick and Kendrew (1957).

${ }^{19}$ For details on the Fourier and Patterson syntheses see Patterson (1934), and the easily accessible Taylor (1967), Holmes and Blow (1980) and in particular Kendrew and Perutz (1949).

${ }^{20}$ Pauling and Corey published a letter announcing the discovery a year before their paper (cf. Pauling and Corey 1950, Journal of the American Chemical Society, 72, 5349).
} 
up" described in the last section. Instead he used model building. Wilkins describes PCB's approach thus:

Pauling had a two-pronged approach to the problem [to work out the structure of protein molecules], which involved thinking about the much smaller and simpler components of these enormous molecules, and then building models of them. [...] He used his quantum mechanical theory of chemical bonding and the latest highly accurate data on bond lengths and angles to determine what these relative positions might be [...] Pauling built three-dimensional models of possible structures, to see how the different components might fit together into a physically and chemically stable molecule. (Wilkins 2003, 158p.)

That is, on the basis of stereochemical data, Pauling determined the molecule's structure starting from the components towards the whole structure. Bond angles and lengths set the constraints, which the three-dimensional scale model of the molecule had to satisfy.

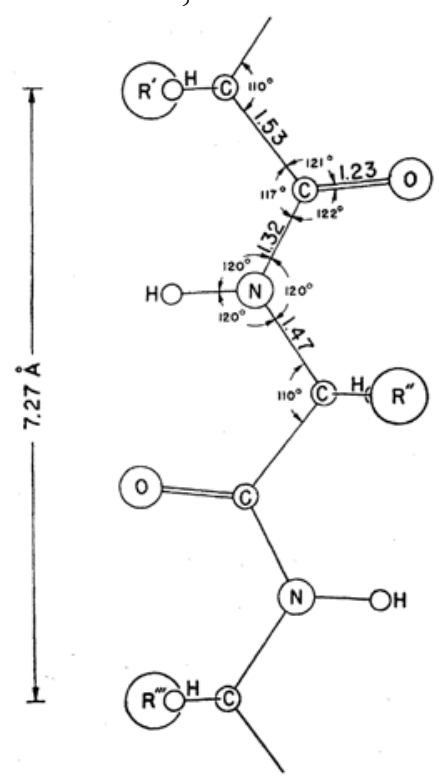

Fig. 2 PCB's alpha helix including bond angles and distances. To be discussed in the next section.
The historian Horace Judson suitably characterizes Pauling's models as "open three-dimensional puzzles in which the individual pieces to be fitted together already carried many of the limitations of angles, lengths, and sizes" (Judson 1996, 62). Bond angles, distances, and kind (single or double), were set. The puzzle solving occurred on the single bonds:

All the bond distances were known and all the bond angles. However, there can be fairly free rotation about bonds called single bonds (but not, by contrast, about double bonds), and the exact configuration of the atoms in space depends on just how these angles of rotation are fixed.(Crick 1989, 55; my italics) The problem is rather like a three-dimensional jig saw puzzle with curious pieces joined together by rotatable joints (Crick 1954a, 57). ${ }^{21}$

Notice that in this quote Crick does not even mention the only direct evidence of the structure of the molecules available ${ }^{22}$, which figured only at the periphery of Crick and Watson's model building but was so central to Franklin's approach: X-ray data. Franklin, who wanted to work out the structure of the molecule from the x-ray data, wasn't prepared to pursue model building. Models, for her, had a very low epistemic value:

Rosalind saw [Bruce Fraser's three-stranded model], and her view was what she felt about all models: 'That's very nice - how are you going to prove it is the solution?' (Maddox 2002, 162) As Rosalind reasoned: 'How will a model show which structure is right? The Patterson will tell us the structure.' (Gosling cited by Maddox 2002, 184; original emphasis)

All that mattered to Franklin were x-ray data which were the only direct, though complicated, link to the structure of the molecule. Rather than using the model as a means of discovery, Franklin thought that models were the end-products of x-ray data analysis:

I encouraged Bruce Fraser, in our lab, to try out his ideas in a model. Rosalind dismissed our excitement [about model-building] by saying that model-building is what you do after you have found the structure. (Wilkins 2003, 160 ; my emphasis $)^{23}$

\footnotetext{
${ }^{21}$ In his (1989), Crick compares this problem with a flat hand with the thumb at right angles with the index finger. One can move the thumb without altering its distance or angle relative to the other fingers of the hand.

22 "The way to get on, in [Crick's] opinion, was to reject any argument which did not arise from the chemistry of nucleic- acid chains." (Watson 1980, 101)

${ }^{23}$ See also Maddox $(2002,161)$.
} 
Crick and Watson adopted the opposite approach. For them - like for Pauling - building models and solving the puzzles that were set by it came first. However, it wasn't model building, which had been done a long time before Pauling, but rather the faith Pauling put into his models and the experimental data respectively, which proved to be so influential on Crick and Watson:

What Pauling did show us was that exact and careful model building could embody constraints that the final answer had in any case to satisfy. Sometimes this could lead to the correct structure, using only a minimum of the direct experimental [ $x$-ray] evidence. This was the lesson that we learned and that Rosalind Franklin and Maurice Wilkins failed to appreciate in attempting to solve the structure of DNA. That, and the necessity for making no assumptions that could not be doubted from time to time. (Crick 1989, 60; italics added)

In other words, in case it should turn out that the constraints of the model in form of bond angles and distances called for a structure that was incompatible with the $\mathrm{x}$-ray data, the latter had to give way for the former. It was this attitude of Pauling's towards the x-ray evidence later to be adopted by Crick and Watson in their construction of the DNA structure - which Crick even believes to have made the difference between successful discovery and failure:

The main difference of approach was that Jim [Watson] and I had an intimate knowledge of the way the $\alpha$ helix [of protein] was discovered [by Pauling, Corey and Branson (1951)]. We appreciated what a strong set of constraints the known interatomic distances and angles provided and how postulating that the structure was a regular helix reduced the number of free parameters drastically. The King's workers were reluctant to be converted to such an approach. Rosalind [Franklin], in particular, wanted to use her experimental data as fully as possible. I think she thought that to guess the structure by trying various models, using a minimum of experimental facts, was too flashy. (Crick 1989, 68; my emphasis)

In contrast to Franklin, who "wanted to use her data as fully as possible", Crick and Watson, like Pauling, were prepared not to do so. Crick even promotes - rather shockingly to our usual intuitions about science I believe -ignorance of most of the experimental evidence:

Thus, not only is the method of building scale models an extremely powerful one, since it embodies a large amount of data which any successful model must include, but for structures of this type it may well pay to build models without giving much attention to the experimental evidence. [...] There is a case, in fact, for careful model building independent of most of the experimental data. (Crick 1954b, 217; my emphasis)

Crick is not an exception. Wilkins, in his memoir, entertainingly concedes that

Our main mistake was to pay too much attention to experimental evidence. Nelson won the battle of Copenhagen by putting his blind eye to the telescope so that he did not see the signal to stop fighting. In the same way, scientists sometimes should use the Nelson Principle and ignore experimental evidence. (Wilkins 2003, 166; my emphasis)

What then is the reason why Crick, Watson and Wilkins, three Nobel Prize winners, promoted the ignorance of experimental evidence? The reason for this we shall find out in the next section. 


\subsection{The Structure of Proteins}

\subsubsection{A FAILED INFERENCE TO THE BEST EXPLANATION}

Max Perutz was one of the first crystallographers to attempt the deciphering of macrostructures. Like Franklin later was to use the Patterson method in her search for the structure of DNA, Perutz used the Patterson method for investigating the structure of haemoglobin. Perutz reasoned that if "the [haemo]globin molecule consisted of a complex
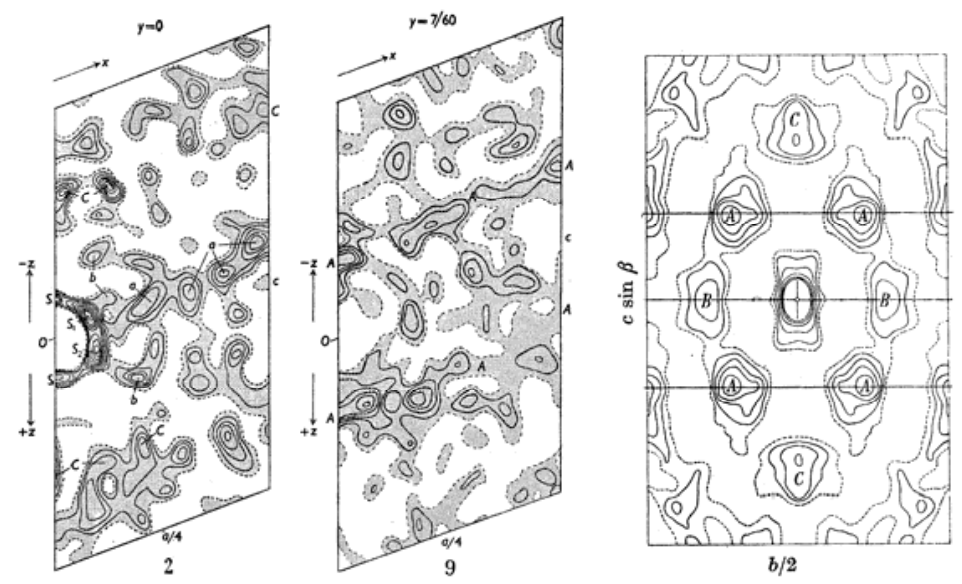

Fig. 3 Rod-like structures of high vector density in the Patterson maps of Haemoglobin. Map 2 exerts a shell-like structure at the origin marked $S$ and an attached rod parallel to the $\mathrm{x}$-axis with high vector peaks separated by $5.1 \AA$ denoted by $a$. Map 9 shows a pair of rod-like structures (A-A). interlocking system of coiled polypeptide chains where interatomic vectors occur with equal frequency in all possible directions, the Patterson synthesis would be unlikely to provide a clue to the structure" (Perutz II, 1949, 474; my emphasis). That is, if the haemoglobin molecule was a closely packed disordered system, the Patterson synthesis would be useless because it could not discern a structure. However, Perutz found that the Patterson contour maps of sections of the crystal exerted rod-like structures parallel to the crystallographic Xaxis (cf. Fig. 3). If one now

produces a Patterson map normal to the $x$-axis one will get the pattern depicted to the far right of Fig. 3. One of these rod-like structures, being taken to represent the polypeptide chains of haemoglobin, is surrounded by six other rods and separated from them by $10.5 \mathrm{~A}$. The underlying structure inferred from the described Patterson maps is depicted in Fig. 4 where a central rod is surrounded by a hexagon whose corners are marked by rods. Perutz model of Fig. 4 seems indeed to be the most straightforward explanation for the data depicted in Fig. $3^{24}$. One can almost "see" the structure in the Patterson maps! And this is exactly the procedure Franklin pursued in trying to discover the structure of the DNA. She too sought to infer the structure from the Patterson map, the only direct available data on the structure of macromolecules. This line of reasoning from the data to the underlying reality of the phenomena is exactly what

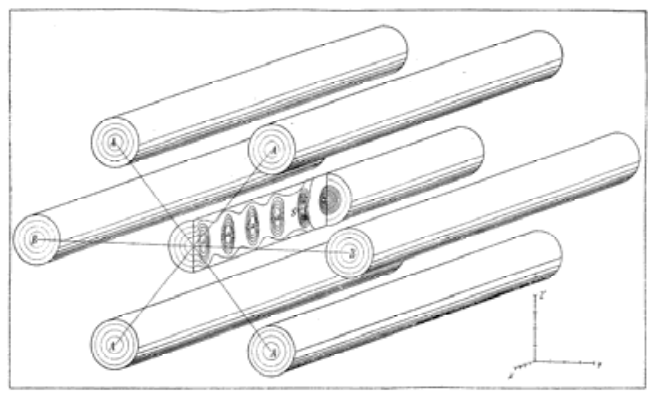

Fig. 4 Inferred underlying structure from the Patterson maps in Fig. 3, also known as the "hat-box" model. the proponents of IBE claim the scientist does and should do. And yet, this straightforward procedure from the data to the structure had its limitations, as we shall see soon.

\footnotetext{
${ }^{24}$ However, it was not. Crick (1952a) showed that Perutz' model of haemoglobin of long parallel chains couldn't be correct. He calculated the Patterson peaks to be expected if such a structure as proposed by Perutz was assumed to be correct (cf. Judson 1996, 527p.). The correct structure of proteins was revealed by Pauling (see below).
} 


\subsubsection{THE MISLEADING 5.1 Á SPOT IN PROTEINS AND HOW TO GET RID OF IT}

In Section 1.2 we were asking why Crick, Watson and Wilkins were promoting the ignorance of evidence. Crick, once again, gives us the necessary clue as to why he and Watson followed Pauling in applying the "Nelson principle":

You must remember, we were trying to solve [the structure of DNA] with the fewest possible assumptions. There's a perfectly sound reason - it isn't just a matter of aesthetics or because we thought it was a nice game why you should use the minimum of experimental data. The fact is, you remember, that we knew that Bragg and Kendrew and Perutz had been misled by the experimental data. And therefore every bit of experimental evidence we had got at any one time we were prepared to throw away, because we said it may be misleading just the way that 5.1 reflection in alpha keratin was misleading. (Crick in Judson 1996, 93; altered emphasis)

Before PCB discovered the $\alpha$ structure of polypeptides, Bragg, Kendrew and Perutz (henceforth BKP) at the Cavendish Laboratory in Cambridge, partly on the basis of the pioneering work by Perutz mentioned in Section 1.3.1., had their go at deciphering the structure. They published a paper in 1950 in which they reviewed and proposed possible structures of alpha keratin (ten in total) ${ }^{25}$. Basing their models on the data recorded by the authority in x-ray crystallography of fibres of that day, Bill Astbury at the University of Leeds, they made the $5.1 \AA$ repeat $^{26}$ a condition the models had to satisfy. The $5.1 \AA$ A repeat was a consequence of the assumption that the helix had an integral symmetry axis.

Crystallographically speaking there was no alternative to this assumption. Two-, three-, four-, or six-fold symmetries are the only possible symmetry axes because only with them can the pattern repeat indefinitely in two or three dimensions (cf. Crick and Kendrew 1957, 140) ${ }^{27}$. J. D. Bernal recalls that

[w] clung to the rules of crystallography, constancy of angles and so forth, the limitation of symmetry rotations to two-, three-, four-, and six-fold, which gave us the 230 space groups, as long as we could. Bragg hung on to them, and I'm not sure whether Perutz didn't too, up to a point, and it needed Pauling to break them with his irrational [i.e. non-integral] helix. (Bernal 1966, 3; my emphasis; also quoted in Olby 1994, 289)

BKP decided that a twofold fibre axis with three residues per turn, equivalent to the model that had been proposed by Astbury and Bell in $1941^{28}$, would fit the Patterson synthesis best. In fact, BKP rejected a model very much akin to Pauling's alpha helix because it did not satisfy the 5.1 A repeat condition (cf. Crick 1989, 58 and Olby 1994, 289). ${ }^{29}$ Pauling himself was first irritated by the 5.1 A spot. He describes his first attempt to unveil the structure of proteins thus:

Although no direct experimental evidence was available about molecular dimensions of simple peptides or closely related substances, I thought the general structure theory should permit predictions to be made. I spent the summer of 1937 in an effort to find a way of coiling a polypeptide chain in three dimensions compatible with the $x$-ray data reported by Astbury. This effort was unsuccessful, which led me to conclude that I was making some unjustified assumption about the structural properties of the molecules. (Pauling in Judson 1996, 62; my emphasis)

\footnotetext{
${ }^{25}$ Bragg, L., J. C. Kendrew, M. F. Perutz (1950), "Polypeptide Chain Configurations in Crystalline Proteins", Proceedings of the Royal Society of London. Series A, Mathematical and Physical Sciences, vol. 203, no. 1074, pp. 321-357.

The repeat of the molecule is the structural unit, which builds up the molecule by repeating itself. In this sense it is equivalent to the crystallographic unit cell.

${ }^{27}$ The $n$-fold screw axis of a structure is defined as the rotation of the structure through an angle of $360^{\circ} / n$ about the axis and a simultaneous translation of the structure parallel to the axis.

${ }^{28}$ Astbury, W. T. and F. Bell (1941), "Nature of the Intramolecular Fold in $\alpha$-Keratin and $\alpha$-Myosin", Nature, 147, pp. 696-699.

${ }^{29}$ Apart from assuming the wrong repeat distance BKP also incorrectly allowed free rotation around the C-N bond in the polypeptide chain.
} 
His failure to build a structure of proteins according to Astbury's data (of $5.1 \mathrm{~A}$ in particular) made Pauling study the structure of the simpler components of proteins: amino acids and polypeptides. However eleven years of investigation revealed that "there wasn't something important that we were overlooking [...] and by 1948 it was evident that there were no surprises about these molecules, really. We had made our information more precise but hadn't changed our understanding in any qualitative sense" (Pauling in Judson 1996, 64.). In 1948 Pauling, lying in bed with a cold on his stay in Oxford as a visiting scholar, solved the problem by drawing on paper the chemical structure of a polypeptide chain including bond angles and lengths from memory and then folding the structure in space. Now, it is not the fact that Pauling used paper as a tool in discovering the structure, as some scholars would be happy to claim (see Klein 2001, and Klein 2003 and in particular Nye in Klein 2003). Rather, it was a purely theoretical idea, which was crucial to Pauling's discovery: Given two identical and asymmetrical objects in space the general, mathematically provable, relation holding between these two objects is a rotation around and a translation along the axis between these objects. If this operation is repeated one arrives at a helical structure (cf. Pauling in Judson $1996,64)^{30}$. Pauling reports that this was the idea that he "had in 1948, and had not had in 1937 " (ibid.). For this idea to work, one had to treat the twenty amino-acid residues not as different but as equivalent:

Back in 1937 I had been so impressed by the fact that the amino-acid residues in any position in the polypeptide chain may be of any of twenty different kinds that the idea that with respect to folding they might be nearly equivalent had not occurred to me. I accordingly thought to myself, what would be the consequences of the assumption that all of the amino-acid residues are structurally equivalent, with respect to the folding of the polypeptide chain? (Marinacci 1995, 124p.; my emphasis)

On the basis of this theoretical idea Pauling gained confidence to ignore Astbury's 5.1 Á spot, which had caused him headaches before (see above). This allowed him to propose a helical structure with a non-integral axis of symmetry. Crick recollects that

[Pauling] had not attempted to make the structure with an integer screw but had let the models fold naturally into any screw they were comfortable with. [...] The fact that his model did not explain the $5.1 \AA$ reflection on the meridian he put to one side. The irony was that Bragg, Kendrew and Perutz had built, among other models, one that was, in effect an $\alpha$ helix, but they had deformed the poor thing to make it have an exact fourfold axis. This made it look very forced, as indeed it was. (Crick 1989, 58; my emphasis)

Again, Pauling, in contrast to BKP put stereochemical considerations - in the quote by Crick paraphrased in aesthetical terms - before the X-ray evidence. Instead of assuming a three- or fourfold axis of symmetry, accommodating the 5.1 A reflection, as BKP did, PCB ignored Astbury's spot and proposed 3.6 amino acids per repeat (i.e. a non-integral axis of symmetry corresponding to $100^{\circ}$ rotation about the screw axis). This was the only model out of five possible ones which satisfied all the stereochemical constraints (cf. Pauling, Corey and

\footnotetext{
${ }^{30}$ This argument can be found on the first paper by Pauling and Corey on the alpha helical structure of proteins: "An amino acid residue (other than glycine) has no symmetry elements. The general operation of conversion of one residue of a single chain into a second residue equivalent to the first is accordingly a rotation about an axis accompanied by translation along the axis. Hence the only configurations for a chain compatible with our postulate of equivalence of the residues are helical configurations". (Pauling and Corey 1950, 206) The same idea, again, is described in Marinacci $(1995,125)$. My thanks belong to Greg Raddick for referring me to the last source. Huggins even earlier than Pauling made another theoretical argument for the helical structure of proteins: „Polypeptide chains extending through the crystalline regions must each have a screw axis of symmetry [i.e. a helical structure], or else two or more chains must be grouped around screw axes or other symmetry elements. The unbalanced forces on opposite sides of a chain which has no screw axis [...] would tend to bend it continuously in the same direction."(Huggins 1942, 197)
} 
Branson 1951, 208) ${ }^{31}$. From the number of the amino acid residues (and an inter-residue nitrogen-hydrogen-bond distance) followed that the helix had to have a repeat of $5.4 \AA$ instead one of $5.1 \AA$ and an inter-residue distance of $1.5 \AA$ (= $5.4 \AA / 3.6)$ (Pauling et al. 1951, 209). Encouragement for his model Pauling found in a study of synthetic proteins by Bamford, Hanby and Happey (1951), which had yielded the 5.4 A spot his model had predicted (cf. Olby 1994, 282p. and Judson 1996, 64pp). Very interestingly, this spot by Bamford et al. was interpreted to be within the limits of error of Astbury's 5.1 A spot:

The Courtauld's scientists [i.e. Bamford et al.], however, shrugged off the difference between 5.26, 5.28, and 5.1 A. much to Astbury's annoyance [...] Whereas Bamford, Hanby and Happey wanted to find a near 5.1 A repeat, Pauling and Corey did not want to. One picture in particular $[\ldots]$ showed quite clearly that the so-called meridional arc at 5.26 A was in fact an off-meridional doublet, and they rightly put the true repeat distance at about 5 1⁄2 A. (Olby 1996 282; original emphasis).

Clearly, both Bamford et al. and Pauling were led by their respective presuppositions in interpreting the available evidence. Whereas Bamford et al. tried to assimilate their finding to the well-known and accepted 5.1A spot, Pauling interpreted the observed value in favour of his model ${ }^{32}$. And yet, Pauling was not content with this "confirmation" of the 5.4 A spot. Even though he left the $5.1 \AA$ spot to one side when he built his model, a year later (1951), he found an explanation for why only a $5.1 \AA$ spot could be observed but not the $5.4 \AA$ spot, which followed from his model. If one presumed that the non-integral helix bends into a superhelix or coiled coil - like ropes laid together into a cable - the single helix due to its experienced deformation would turn into an integral helix and would thus produce the $5.4 \AA \operatorname{spot}^{33}$. In
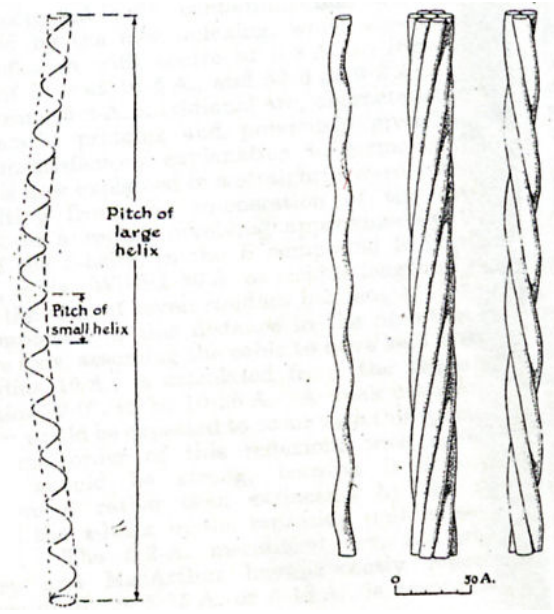

Fig. 5 The coiled coil. Single helices (left) are packed together into superhelical cables and ropes (right). other words, Pauling's model offered the resources for explaining away Astbury's 5.1 A spot in the form of the supercoiling or coiled coil ${ }^{34}$. Although this might seem to be unsound scientific practice, this is exactly what happened without having been denounced by the scientific community.

In the last section we were asking how the noble price winners Crick, Watson and Wilkins could have possibly promoted the ignorance of evidence. In this section we saw why: Astbury's 5.1A spot stood in the way of the "discovery" or rather postulation of the alpha structure of proteins. The Astbury spot was incompatible with helices. Only after Pauling was confident enough - due to his theoretical argument - to ignore this spot, was he in the position to propose his structure ${ }^{35}$.

\footnotetext{
31 This is the structure Pauling later coined " $\alpha$ helix". There was another structure with 5.1 residues per turn, which also satisfied the constraints. Pauling coined it the $\gamma$ helix. However Pauling later rejected this structure (Pauling and Corey 1951, 729; cf. Crick 1954, 200).

${ }^{32}$ This phenomenon, of course, is known as "theory-ladenness" of observations and has been a scorn to philosophers of science. Another most interesting example for theory-ladenness is discussed in Schindler (2007). 33 Pauling and Corey (1953). Crick came up with the same idea almost simultaneously: Crick (1952b). According to Judson (1996, 129) Pauling's paper arrived at Nature only one or two days after Crick's. 34 Although modern research has established irregularities in the coiling, the basic idea of coiled coils is still entirely accepted (cf. Gruber and Lupas 2003).

35 There is admittedly another, sociological, dimension to Pauling's discovery. Pauling, in contrast to BKP was not trained as a crystallographer and therefore found it much easier to reject one of the fundamental assumptions, crystallographers were working with at the time, namely the assumption that crystals always had to have an integral axis of symmetry (see the quote by Bernal above on page 12) This, once again, confirms Thomas S.
} 


\subsubsection{DERIVED PREDICTIONS FROM PAULING'S ALPHA-HELIX OF PROTEIN MOLECULES}

After PCB had proposed their alpha helix with 3.6 residues per repeat of length $5.4 \AA$, Perutz realized that if this model were correct, a reflection at $1.5 \AA$ had to be observed corresponding to the height between the amino-acid residues ${ }^{37}$. This reflection had not been observed before but Perutz realized that the photographs of protein taken by Astbury, on which PCB.'s model was based, could not record this reflection because the used apparatus precluded the observation of such a reflection. Therefore, instead of using a flat plate camera, as Astbury had done, Perutz employed a cylindrical film, which allowed for a Bragg angle of $31^{\circ}$, which was necessary for recording the $1.5 \AA$ A reflection (cf. Fig. 6; see Perutz 1951a, b and Perutz 1998). Crick informs us that ,this technique is almost as old as X-ray crystallography, but it was neglected in this field before the work of Perutz" (Crick, 1954, 211). That is, PCB's model led the way to an impressive novel prediction. We can put this more strongly: the PCB model seems to have been the precondition for modifying the experimental apparatus and for making the novel observation.

Although the $1.5 \AA$ reflection could be read off directly from the model, the general properties of the x-ray diffraction photographs, which were to be expected from an $\alpha$-helix were unknown. "In response to the proposal by Pauling and Corey $^{38,}$, and in order to establish a link between the whole model and the evidence, Cochran, Crick and Vand (1952) developed a theory of the effects of helices in X-ray diffraction patterns, which I shall introduce in the next section.

\section{THE CCV THEORY OF HELICAL X-RAY DIFFRACTION}

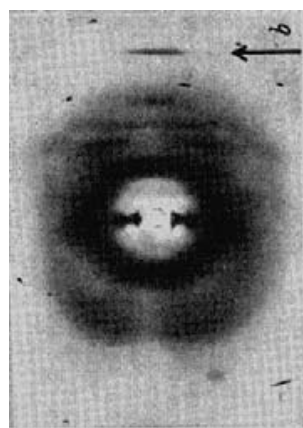

Fig. 6 Perutz's recording of the $1.5 \AA$ spot (marked by a reversed $\mathrm{b}$ at the top of the picture $^{36}$ ). Due to the tilting of the specimen the reflection appears only on one side (here: the upper side) of the photograph.

In x-ray diffraction of organic fibres like DNA the fibre axis is conventionally mounted along the vertical of the photographic film or plate. By rotating the fibre around the fibre axis whilst bombarding it with $\mathrm{x}$-rays one obtains the whole reciprocal lattice $e^{39}$ on the same photograph (not just two dimensions as in a static photograph) because the lattice runs through different angles relative to the $\mathrm{x}$-ray source thus satisfying all the Laue conditions, which are met whenever the path difference between the waves is an integral multiple of the wavelengths, resulting in positive interference. If the Laue conditions are not satisfied the waves cancel each other out (negative interference).

\footnotetext{
Kuhn's dictum that new ideas are brought into a science by newcomers or outsiders. See Schindler (2007) for another impressive example in the realm of the plate tectonic revolution.

${ }^{36}$ Dr. John Lydon informed me that the picture in Perutz's Nature paper was printed the wrong way around. The picture here appears in its correct orientation, which is why the letter $b$ is tilted.

37 This, in fact, was predicted by Pauling and Corey $(1951,243$, "The structure of hair, muscle and related proteins"). However, from the (historical) literature it seems as though Perutz had realized this consequence by himself. Cf. Olby (1993, 234), Judson (1996, 69), Crick (1989, 59), Perutz (1998).

38 "The structure of synthetic polypeptides", Proceedings of the National Academy of Science U.S.A., 37, 241.

39 That is, short distances on the photograph are actually large distances within the crystal lattice and vice versa.
} 


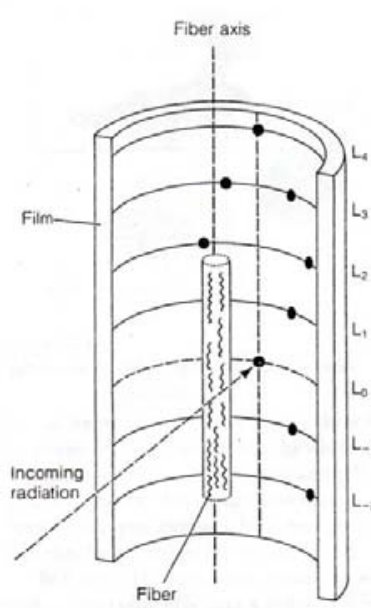

Fig. 7 Rotation photograph. The specimen is mounted vertically. The spots fall onto the layer lines of the film marked by $\mathrm{L}_{i}$.

asking the theoretician in his lab, Alec Stokes, which x-ray diffraction consequences such a helical structure would entail ${ }^{42}$. Cochran, Crick and Vand (henceforth: CCV) first derived predictions for a continuous and then for a discontinuous helix. Their theory predicted

that layer lines to which only high-order Bessel functions contribute would be weak or absent, and that those to which very low orders contribute would be strong. (Cochran et al. 1952)

This amounted to meridional absences and a cross-ways pattern on the x-ray photographs. Fig. 8 depicts this pattern to be expected (right) from a helix (left).

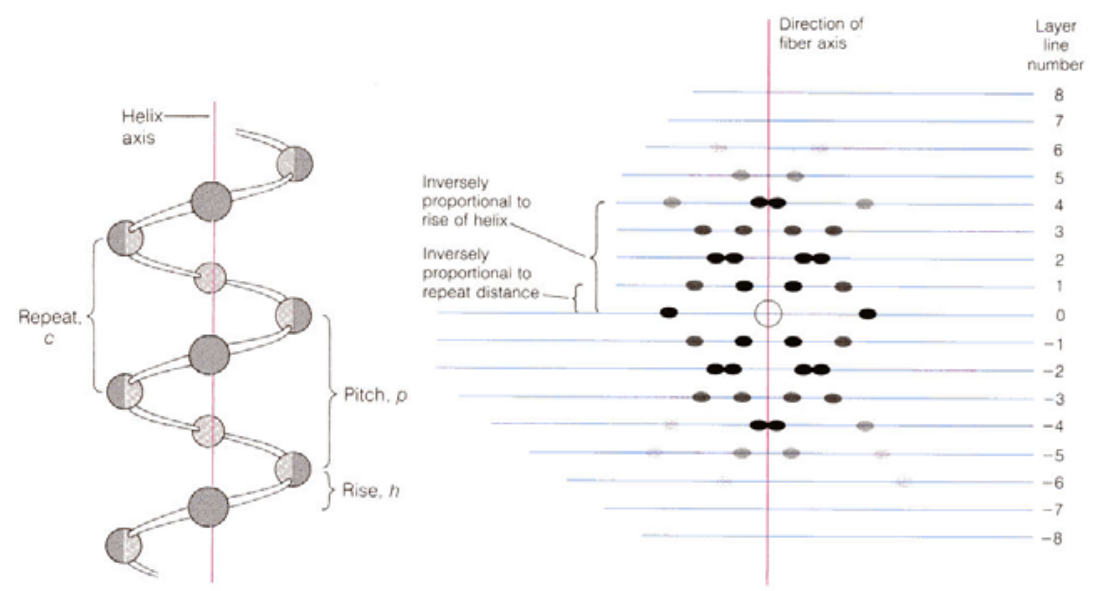

Fig. 8 Schematic drawing of a helix (left) and CCV's x-ray pattern prediction of such a helix (right). Notice the reciprocal relationship between the parameters of the helix (repeat, rise, pitch) and the predicted x-ray pattern. Also compare the prediction with the B form in Fig. 9.

\footnotetext{
${ }^{40}$ Notice that the repeat in a fibre is a rather different thing from the repeating unit in a crystal (the unit cell).

${ }^{41}$ Good introductory readings are: Crick and Kendrew (1957), Matthews et al. (2000), Astbury Fundamentals of fibre structure, Cracknell (1969), Lipson (1970) and Holmes and Blow (1980). For an advanced resource see van Holde et al. (2006).

42 "When I had finished reading Pauling's $\alpha$-helix paper I was puzzled that he seemed not to have a way of calculating X-ray diffraction from the structure” (Wilkins 2002, 160; also see Judson 1996, 95p.).
} 
Remember again that the observed pattern is reciprocal to the actual structure. The distance between the layer lines then corresponds to the repeat of the helix, the "height" of the cross corresponds to the rise of the helix (Fig. 8), and the angle between the arms of the cross deliver the parameter of the width of the helix. With the CCV theory the interpretation of the $\mathrm{x}$-ray pictures became an unequivocal matter:

Armed with the appropriate theory [i.e. CCV's theory] it is often possible to recognize the helical nature of a fiber structure at a glance, and sometimes to specify the main parameters of the helix and its subunits with very little trouble indeed. (Crick and Kendrew 1957, 145; my emphasis)

The CCV theory thus established the deductive link between the structure of the model and the x-ray diffraction data. Only through this link from the top-down the data gained the certainty and definiteness obvious from the quote above. As we shall see in the next section the CCV theory was going to play a crucial part in the discovery of the DNA structure.

\subsection{THE ROLE OF THE CCV THEORY IN THE DISCOVERY OF THE DNA STRUCTURE}

Although the CCV theory was developed in response to Pauling's helical model for proteins, it of course applied to any sort of molecule with a helical structure. Cochran, one of the people, who hit on the CCV theory independently, supposes that

The main value of this work [of the helical diffraction theory], seen in retrospect, is that it was the first step on the road to the discovery of the structure of DNA by Jim Watson and [Francis] Crick. (Cochran 1987, 16)

In order to appreciate the value the CCV theory had for the discovery of DNA, we first of all need to consider briefly the x-ray diffraction pictures of crystallized DNA.

Fibres, built up of polymers (long molecule chains consisting of monomers) do not possess the order to be met in crystals. Whereas in crystals the molecules have a set orientation along the three crystallographic axes, in fibres the monomers are in random orientations. Some fibres are said to be crystalline because they consist of small regions which are perfectly crystalline, although this order is not consistent throughout the whole fibre but only local; each small crystalline region will have a different orientation from the others. In 1951 Franklin and Gosling observed that one had to apply a high degree of humidity in order to obtain a high degree of crystallinity in the DNA. When they tried to increase the crystallinity of the DNA by increasing the relative humidity above $75 \%$ a new $x$-ray pattern resulted. They dubbed the latter the "wet" or simply "B" form and the form at a relative humidity of $75 \%$ the "crystalline" or " $A$ " form. Because the A form has crystalline order it produces sharp spots, whereas the B form - due to the random orientations of its molecules produces smears (Fig. 9) ${ }^{43}$.

\footnotetext{
${ }^{43}$ Before Franklin had established the two pure forms, it was assumed that there was only one form. In 1938 Astbury and Bell had obtained the first x-ray diffraction picture of DNA with a marked $3.4 \AA$ spot but the layer lines were not separated by $34 \AA$ (a feature of the B pattern) but by roughly $27 \AA$ (a feature of the A pattern). The repeat distances were much clearer for the B than for the A form. Since the A form in regard to the B form is shrunk by $25 \%$ the interesidual distance had to be $2.8 \mathrm{~A}$. In the $\mathrm{B}$ form the distance between the layer lines was $34 \mathrm{~A}$ and thus had to be $28 \mathrm{~A}$ for the $\mathrm{A}$ form.
} 

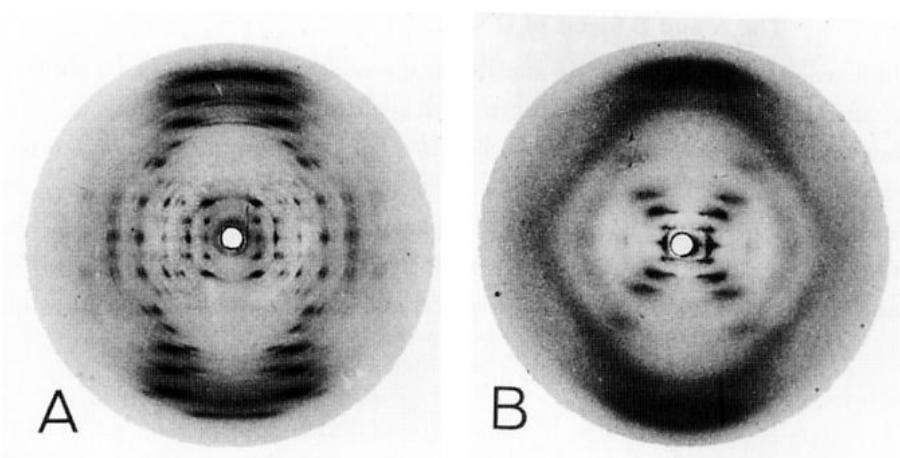

Fig. 9 X-ray photographs of the A ("crystalline") and the B ("wet") form of DNA (see Franklin and Gosling 1953a, Fig.1 and Fig. 4). Whereas the A form contains sharp spots the B form has a cross of smudges. Both forms display meridional absences of reflections and strong black arcs on the top and the bottom of the photograph (A: $2.8 \AA$, B: $3.4 \AA$ ).

Because the A form was crystallographically more telling in that it contained sharper spots due to a more ordered underlying structure, Franklin preferred the A form over the B form:

Franklin had decided that there were sufficient discrete reflexions in the diffraction pattern of the A form to settle the question of the existence of helices of this form by an objective crystallographic analysis, without any assumptions having to be made. (Klug 1968, in Watson 1980, 154; my emphasis) ${ }^{44}$

On the other hand, Crick and Watson were concentrating on the B-form, because it was a straightforward confirmation of the X-shaped pattern predicted by the CCV theory. And this is the exactly the reason for Watson's astonishment, when Wilkins showed him the B-form of DNA, which Franklin had produced (compare the predicted X shaped pattern in Fig. 8 and the B form in Fig. 9):

The instant I saw the picture my mouth fell open and my pulse began to race. The pattern was unbelievably simpler than those obtained previously ("A" form). Moreover, the black cross of reflections which dominated the picture could arise only from a helical structure. With the A form, the argument for a helix was never straightforward, and considerable ambiguity existed as to exactly which type of helical symmetry was present. With the B form, however, mere inspection of its X-ray picture gave several of the vital helical parameters. (Watson 1980, 98; my emphasis)

Again, we here have a very strong form of theory-ladenness (cf. page 14). Without the CCV theory, the B-pattern to Watson would have been meaningless. Even more so, the B pattern gained an unambiguousness it would have not possessed without the theory. Asked by the historian Judson, whether Watson knew any of the calculations Franklin had done on the Bpattern, Watson denied and declared that merely "seeing" the photograph had been enough for him to construct the model of the DNA:

I had a clear memory of it, which could help me with the model because the way the arms of the cross lay in the diagram showed where the main mass of the helix [phosphate groups] had to be [...] If you saw - that's about it. (Watson in Judson 1996, 137; my emphasis)

\footnotetext{
${ }^{44}$ See also Klug (2004, 20p.), Maddox (2002, 170) and Judson (1996, 114).
} 
The reverse is also true. One year before CCV had developed their X-ray diffraction theory and two years before Franklin discovered the B pattern, Astbury had put his student Beighton 1951 onto thymus DNA, who managed to produce a very pure form of this very Bpattern (cf. Fig. 10). Yet, Astbury and Beighton rejected the photograph because they thought it was a mix:

Strangely enough, Astbury was disappointed by these results and both Beighton and he obviously thought that the 1938-39 Bell pictures represented pure forms, whereas Beigton's B form was a mixture - with few X-ray spots of course! (Olby 1994, 379; my italics) $)^{46}$

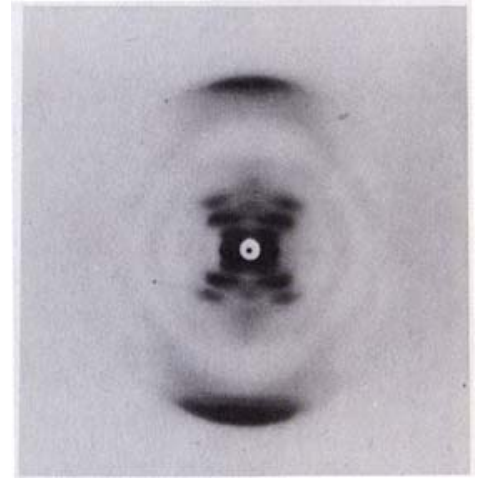

Fig. 10 Beighton's B form pattern ${ }^{45}$. Compare with pattern B in Fig. 9

Clearly then, Astbury and Beighton did not understand what they were seeing because they did not possess the theory, which would have told them unequivocally that the B-pattern was the purest and clearest one could get. ${ }^{47}$ Equipped with the same theory as Watson, Wilkins and Stokes, too, realized that Stokes calculations fit Franklin's B pattern very well. When they mentioned this to Franklin she responded angrily "how dare you interpret my results!" (Wilkins 2003, 161) And yet, also Franklin could not escape the conclusion that the consequences derived from a helix by CCV fit fantastically well with her B-pattern and thus made the helical structure for this pattern undebatable ${ }^{48}$.

\section{KilLing the HeLiX}

And yet, rather awkwardly, Franklin wrote, in the same year she had produced this B-form $(1952)^{49}$, a death note for the helix for the A form which read:

\footnotetext{
45 This is a copy of Olby's reproduction of Beighton's original photograph (Olby 1994, plate 17). Olby informed me that the photograph was lost by his publisher MacMillan. Crick, in his foreword to Olby's The Path, mentions this picture due to Olby's research to have been a "complete surprise even to those who were actively working in the field" (Olby 1972, vi)

${ }^{46}$ I asked Robert Olby where he received this information from. He wasn't so sure - after all he wrote The Path more than 30 years ago - but in his memory he had talked to Preston and Rudall.

47 Olby $(1972,436)$ supports this conclusion.

48 Dr. John Lydon informs me that the match between theoretical predictions and the observed pattern was only accurate for the geometrical pattern, i.e. for the positions of the reflections. In fact, the predictions and the observed pattern disclosed a mismatch of $90 \%$ ! Normally, the R(eliablility)-factor crystallographers are working with allows for a mismatch of 20-30\%. Still, scientists accepted the double helix because "it was so beautiful it just had to be right!" (my own wordings of a statement by John Lydon; personal communication). Richard Dickerson supports this statement by saying that " $[\mathrm{t}]$ he $\alpha$ helix was accepted, not because it fitted Patterson maps or any other x-ray data, but because it looked right" (Dickerson 2005, 61; my emphasis). Due to Wilkins work in the aftermath of Crick and Watson's proposed model the mismatch could be reduced significantly. According to Klug $(2004,24$ p.) this process took seven years. But the final "formal crystallographic proof of the double helix and the base pairing did not come until 1979, when Drew and Dickerson [1981] solved the structure of a dodecameric DNA oligonucleotide of defined sequence, by using the totally objective heavy atom method." Crick concurs by saying that "The double helical structure of DNA was thus finally confirmed only in the early 1980s. It took over twenty-five years for our model of DNA to go from being only rather plausible, to being very plausible (as a result of the detailed work on DNA fibers), and from there to being virtually certainly correct. Even then it was correct only in outline, not in precise detail [...] The establishment of the double helix could serve as a useful case history, showing one example of the complicated way theories become "fact"”. (Crick 1989, 74; original emphasis; see also footnote 48 of this paper).

49 This was the picture Franklin later was to reproduce in her Nature article alongside Crick and Watson's groundbreaking announcement of the double helix.
} 
It is with great regret that we have to announce the death, on Friday $18^{\text {th }}$ July, 1952, of D.N.A. helix (crystalline). Death followed a protracted illness which an intensive course of Bessel injections had failed to relieve ${ }^{50}$. A memorial service will be held next Monday or Tuesday. It is hoped that Dr. M.H.R. Wilkins will speak in memory of the late helix. (Franklin and Gosling 1952, quoted in Wilkins 2003, 182)

The reason for this death note of the helix for the crystalline A form was one of Franklin's shots of this form, which displayed "double orientation", i.e. "the crystallites were not in random orientation about the fibre axis" and the pattern showed clear differences in the intensities of the reflexions on the two sides of the axis (Franklin and Gosling 1953b; see also Olby 1974, 370p.). This was irreconcilable with a helical structure, as Wilkins conceded later:

Stokes and I could see no way round the conclusion that Rosalind had reached after months of careful work. It seemed, in spite of all previous indications, that the DNA molecule was lop-sided and not helical. (Wilkins 2003, 182)

Judson $(1996,112)$ informs us that "[p]icture and fibre were unique, fortuitous, impossible to duplicate despite many attempts. Franklin came to set great store by this picture", which she described as being "due either to a mechanical accident to the fibre or to preferential orientation of the crystallites which lie near the surface" (Franklin and Gosling 1953b, 683) but concluded that "it seems unlikely that [double orientation] could have occurred at all if the individual crystallites had a high degree of symmetry about the fibre axis" (ibid., 684), i.e. Franklin was positive and was able to convince Wilkins and Stokes that asymmetry in the form of the double orientation was not an accident but an original feature of the structure.

When Watson saw Franklin's "antihelical" evidence, he "decided to take a full explosion" on Franklin because Crick had assured him that Franklin's antihelical results were "a red herring":

Without further hesitation I implied that she was incompetent in interpreting X-ray pictures. If only she would learn some theory, she would understand how her supposed antihelical features arose from the minor distortions to pack regular helices into a crystalline lattice. (Watson 1968, 96; my emphasis)

Obviously, it was again theory (in this case the theory of the coiled coil), which gave Crick and Watson the confidence that Franklin's results could not possibly be a threat to their assumption that the DNA was helical. According to Crick the asymmetry Franklin had found in one of her A patterns could be explained away by a small and unusual asymmetry in the parallel packing of the helical molecules in the specimen (Judson 1996, 118 and Olby 1996, 370). Crick described his and Watson's general attitude towards Franklin's evidence thus:

When she told us DNA couldn't be a helix, we said, 'Nonsense'. And when she said but her measurements showed that it couldn't, we said, 'Well, they're wrong'. You see, that was our sort of attitude. (Crick in Judson 1996, 118)

Crick and Watson's dismissive attitude was justified on grounds of their model and the CCV theory, which established the link between model and evidence. Model-building and theory construction provided the backdrop against which evidence was to be assessed and categorized into "good" or "bad". Franklin lacked these resources from the "top-down" and thus was almost doomed to fail in unveiling the structure of the DNA.

\subsection{APPRECIATING ALL EVIDENCE - IN VAIN}

Franklin's attitude towards the structure of the DNA before Crick and Watson's discovery has been described - most notably by Watson in his Double Helix - as being ideologically

\footnotetext{
${ }^{50}$ Obviously, with "Bessel injections" Franklin was referring to the CCV theory.
} 
"antihelical" ". However, Franklin's collaborator of her later years Aaron Klug (1968) has done away with this simplification.

[Her attitude] might be more accurately described as one of questioning; the question being whether the structure of B - undoubtedly helical in her view - also applied to the crystalline structure A. (footnote in Klug 1968 in Watson 1980, 154)

As mentioned above, Franklin "set great store" by her anthelical A form photograph. Although Franklin according to Klug and also Gosling ${ }^{52}$ did not doubt that the B-pattern indicated an $\alpha$-helix, she tried to find other structures, which were compatible with her antihelical A form. As Crick pointed out, Franklin "wanted to use her experimental data as fully as possible" (Crick 1989, 68) and so she attempted to find a structure that would fit all the data available. Franklin unsuccessfully considered a "figure of 8 structure" (Judson 1996, 132), "bananas" and "double sheets" (ibid., 128). Klug summarizes Franklin's premises thus:

[A]lthough there were clearly helices present in the B structure, these might be so distorted, or even undone, by the intermolecular bonds in the crystalline A structure that she had to consider non-helical structures. (Klug 1968 , in Watson 1968,155$)^{53}$

Franklin herself said that

the helix in the wet state is therefore presumably not identical with that of the crystalline state (Franklin in her annual report; Judson 1996, 111)

Because Franklin did not want to commit to any particular hypothesis before she wasn't compelled by the evidence to do so and had therefore to take seriously every single piece of evidence. This led to some sort of "deadlock", which did not allow her to form a coherent hypothesis of the structure of DNA. Watson, in Crick's wordings, puts this point thus:

Jim [Watson] was little more brash [sic], stating that no good model ever accounted for all the facts, since some data was bound to be misleading if not plain wrong. A theory that did fit all the data would have been "carpentered" to do this and would thus be open to suspicion. (Crick 1989, 59p.; original emphasis)

\section{Conclusion}

In this paper I tried to make available to philosophical discussions one of the most exciting and historically most well investigated episodes in the history of science. This was done by discussing the historical material against the backdrop of the currently "received view" of scientific models and their relation to the theory and the phenomena. This received view has the model as some sort of "simplification", "distortion", or "idealization" of the real system and locates it between theory and the world allowing the application of the former to the latter. Both of these assumptions cannot be confirmed with the present case.

Contrary to the received view, it was not the model (as a sort of hypothesis about the structure of the DNA at the model's core), which mediated between theory and world, but rather the theory developed by Cochran, Crick and Vand, which fulfilled the mediating role between model and the x-ray diffraction photographs. However, calling the theory's role merely a mediating one would not do justice to the case. The theory's role has to be articulated in much stronger terms: the theory established the deductive link between the model and the data. Only through the theory were the data endowed with a meaning, which

\footnotetext{
51 See also Hamilton (1968).

${ }^{52}$ Klug (2004), Gosling in Maddox (2002), Judson (1996).

${ }^{53}$ She was thinking of the A form as an unwound version of the helices in the B state (rather, I imagine, like the $\beta$-sheet structure is to the $\alpha$-helix in proteins and polypeptides) (see Klug 2004, 25).
} 
could be read off the x-ray photographs at a glance. Interestingly, the evidence gained a certainty it did not possess prior to the deductions from the model through the CCV theory ${ }^{54}$. This was impressively evidenced by the fact that Astbury and Beighton could not appreciate the value of the very clear B pattern they had obtained long before Franklin.

In regard to how the nature of models is standardly construed, as pointed out in the introduction already, it is hard to see in what sense Crick and Watson's model is to be considered a simplification or idealization of the real structure of DNA. Before Crick and Watson nobody knew how the real structure looked like so there was no way of idealizing the real structure. Rather, Crick and Watson postulated the structure, as they themselves declared in their seminal paper (Crick and Watson 1953, 737) ${ }^{55}$. Crick and Watson did not infer the structure from the evidence. Yet, exactly this is what Rosalind Franklin tried to do. She committed herself to an approach very much akin to what Cartwright et al. think is the typical approach in model-building and what the proponents of the Inference to the Explanation hold to be good scientific practice ${ }^{56}$. Rather than postulating a structure, Franklin started from the only direct evidence on the DNA structure available and used the mathematical technique of the Patterson synthesis in an attempt to infer the (model of the) DNA structure from those $\mathrm{x}$ ray photographs. She explored many different hypotheses that would account for both the A and the B pattern of x-ray photographs. However, she was not able to infer the best explanation due to the fact that she, in consultation with her colleagues Wilkins and Stokes, had ruled out a helical structure for the A pattern and thus saw herself confronted with the apparent need to find another hypothesis for the A pattern, which was going to be different from the structure of the B pattern. This situation Watson described as a deadlock (see last section). In contrast to Franklin, Crick and Watson chose a procedure from the "top-down". Probably based on the theoretical argument for helical structures in proteins by Pauling (see Section 1.3.2), Crick and Watson assumed a helical structure throughout without ever doubting this assumption ${ }^{57}$. The crucial difference, then, between Franklin's and Crick \& Watson's approach, which Crick even explicates himself (see page 10), was their respective attitudes towards the evidence. Whereas Franklin tried to "use her data as fully as possible", and on the basis of the data attempted to infer the DNA structure, Crick and Watson, in contrast were very cautious in regard to the validity of the evidence and were led mainly by theoretical considerations and theoretically plausible arguments. Franklin's and Crick \& Watson's respective attitudes are a consequence of their respective approaches: whereas Franklin, due to her "bottom-up" approach, had no grounds for rejecting any piece of evidence as being "bad" but had to consider every piece of evidence she could get hold of, Crick and Watson, again due to their "top-down" approach, were happy to neglect any piece of evidence at any time, in case that piece of evidence would not fit with their commitment to the helical structure. Although this at first glance surely seems to be a rather irrational behaviour, in face of the history, it seems to be the more reasonable one. In fact, we observed in this essay that taking particular evidence too seriously blocked some researchers from making discoveries, which were made by others, which ignored the same evidence. This is not

\footnotetext{
${ }^{54}$ See Schindler (forthcoming) for a discussion of this phenomenon on a broader scale.

55 The postulation of "imaginary entities" seems to be a rather common characteristic of scientific models, although philosophers of science have missed this point entirely hitherto. See Schindler (2006) for details.

${ }^{56}$ In the introduction I have pointed out that Cartwright is committed to some form of discovery procedure "from the bottom-up". I have ruled out induction as an appropriate candidate, which leaves only IBE.

${ }^{57}$ In Olby (1994) one can read a quote by Crick, where he says that the helical confirmation ,,was very much in the air just before the alpha helix [of proteins] [...] Pauling obviously thought that way; Bragg was convinced things were helical. They were all building helical models. I would say, you would be eccentric, looking back, if you didn't think DNA was helical“". (Crick 1968 in Olby 1994, 294). The critical reader, however, should ask as to why helices were so ,fashionable“ (Olby 1994 and any other piece of literature I have read on the discovery of the DNA fails to do so!). The reason, as I firmly believe has to be sought in Huggins's and Pauling's theoretical arguments in favour of helices (see page 13).
} 
only true for Franklin, who took too seriously her odd A pattern, which indicated a structure for the DNA different from a helix, but also for Bragg, Kendrew and Perutz, who took too seriously Astbury's 5.1A spot, which lead them to rule out the correct alpha structure for proteins (see Section 1.3.2) s $^{58}$. Thus, given all the evidence considered in this essay, one could conclude that the DNA structure was discovered from the "top-down".

\section{Epilogue: Chargaff's Ratios}

In many textbooks of biochemistry and historical accounts the base ratios of $1: 1$ between the number of adenine $(A)$ and thymine $(T)$ molecules and between the number of guanine $(\mathrm{G})$ and cytosine (C) molecules, discovered by Erwin Chargaff, are introduced as being the crucial information Crick and Watson built their model upon. If you know, how the bases fit together - so the reasoning goes - you know how the double helix must be built. Because some readers might raise this as an objection against the conclusions drawn in this paper, it is necessary to set straight this prejudice about the role the Chargaff ratios really played in the discovery of the DNA structure. First of all it should be noted that Crick and Watson tried to build models with the bases outside the sugar and phosphor strands due to the complexity resulting in having the bases between the chains being too high (see Watson 1980, 103). However, when this did not lead to the desired success, Watson, at some point of despair, decided to put the bases inside the sugar and phosphor strands. But even then, Chargaff's ratios did not play any part whatsoever, as should be more than plain from the following quotes:

The data of Chargaff's, you know, wasn't all that convincing unless you wanted to believe it. (Crick in Judson 1996, 154) [W] hen we came to build the structure we did not initially use that idea [of 1:1 ratios]. We didn't do it until we were driven towards it. [W] never knew whether Chargaff's rules had some completely extraneous functional reason, and so we didn't put that in[to the model]. The Chargaff rations just fell out at the end. (Watson in Judson 1996, 148; original emphasis) Chargaff's rules then suddenly stood out as a consequence of a double-helical structure of DNA. (Watson 1980, 114) When the final model of DNA was discovered - more or less by accident - it wasn't Chargaff's rules that made the model, but the model that made the rules. (Donohue 1978, 135; my italics; see also Judson 1996, 637)

Rather than being a piece of information that went into the construction of the model, the 1:1 base ratios were a consequence of the model: they are explained by the A-T and G-C base pairing 59 . The corresponding base pairings in the structure, in turn, were "forced onto" Crick and Watson not by the experimental finding by Chargaff, but rather by the fact that the strands had to run antiparallelly, which again was a consequence of Franklin's finding that the crystallographic unit of the A-pattern of DNA was C2-symmetrical ${ }^{60}$. But even if one were

\footnotetext{
${ }^{58}$ See also Section 4.1 where Astbury rejected a helical structure for proteins for reasons to do with density measurements. It so happens that similar observations can be made in other sciences too. Einstein, for instance, neglected the positive results of an ether drift experiment carried out by Miller in 1920s, which "caused a major upheaval in the scientific community" and many to reject Einstein's theory of relativity (Hentschel 1992, 604). Another neat example is the controversy between Millikan and Ehrenhaft about whether there were smaller parts charges than the ones measured for electrons by Millikan. Holton (1978) has shown that Millikan disregarded a large amount of the oil drops he gained in his experiments for no apparent reason. Ehrenhaft discounted Millikan's "style" that "piles up "hypotheses and corrections". His "style", in contrast, was to "proceed from the direct facts" and to admit all measurements in his analysis (see ibid, 73, 78 and 79 in particular).

59 Before Crick and Watson's model Chargaff's ratios were unexplained. They seem to have a similar epistemological status like Boyle's or Kepler's law before they were explained by the kinetic theory of gases and Newton's theory of gravitation respectively.

${ }^{60}$ This, Franklin herself and everybody else who was aware of the contents of her report to the Medical Research Council (Perutz, Wilkins and Stokes) for some strange reason failed to realize (cf. Judson 1996, 142). For the implications of the C2 or "face-centred" symmetry group see Perutz's explications in Judson (1996, 102). The fact that the DNA structure belongs to the C2 symmetry group was contained in Franklin's MRC report, which Perutz passed on to Crick and Watson. Although this action has caused some controversy as to
} 
still to believe that Chargaff's ratio did play a part in the discovery of the structure of DNA, Crick and Watson's presupposition that the structure was helical, which was the focus of this paper, is not affected ${ }^{61}$.

\section{ACKNOWLEDGEMENTS}

Suppressed for blind review.

\section{BiBLIOGRAPHY}

Achinstein, P. (1968), Concepts in Science: A Philosophical Analysis, Baltimore: John Hopkins Press.

Astbury, W. T. (1933), Fundamentals of fibre structure, London: Oxford University Press : H. Milford.

Astbury, W. T. and F. Bell (1938), "Some recent developments in the X-ray study of proteins and related structures", Cold Spring Harbor Symposia on quantitative biology, vol. 6, 109-118.

Astbury, W. T. and F. Bell (1941), "Nature of the Intramolecular Fold in $\alpha$-Keratin and $\alpha$ Myosin", Nature, 147, 696-699.

Astbury, W. T. (1947), "X-ray studies of Nucleic Acids", Symposia of the Society of Experimental Biology, 1, Nucleic Acid, p. 66, Cambridge University Press.

Bailer-Jones, D. (1999), "Tracing the Development of Models in the Philosophy of Science", in: L. Magnani, N.J. Nersessian, and P. Thagard (eds.), Model-Based Reasoning in Scientific Discovery, Kluwer Academic, New York.

Bamford, C.H., W.B Hanby, F. Happey (1951), "The Structure of synthetic polypeptides. I. X-ray Investigation", Proceedings of the Royal Society of London. Series A, Mathematical and Physical Sciences, vol. 205, No. 1080, pp. 30-47.

Bernal, (1966), Opening Remarks to: "Principles of Bimolecular Organization", Ciba Foundation Symposium, London, 1-6.

Bogen, J. and J. Woodward (1988), "Saving the Phenomena", The Philosophical Review, vol. 97, No. 3., pp. 303-352.

Black, M. (1962), Models and metaphors: studies in language and philosophy, Ithaca, N.Y.: Cornell University Press.

Bragg, L. (1962), "X-ray Analysis of Proteins", The Proceedings of the Physical Society, Section B, vol. 65, no. 395, 1 November, 834-846.

Bragg, L. (1965), "First stages in the x-ray analysis of proteins", Reports on Progress in Physics, 28, 1-14.

\footnotetext{
whether Perutz had acted ethically the information contained in the MRC report was non-confidential (cf. Judson 1996, 141p.).

61 The same is true for Donahue's advice that the bases had keto and not enol configuration, which was necessary for being able to pair the bases inside the sugar-phosphate backbones. This claim is also true for the insight that there were not three but only two strands of DNA. Why does the DNA consist of two and not of three chains? Watson $(1968,171)$ in his Double Helix stated that the reason was that "important biological objects came in pairs". Crick called this later "non-sense" (cf. Judson 1996, 143). In fact, both Pauling and Crick and Watson built models with three instead of two chains because they were relying on density measurements of DNA by Astbury (1947) which determined a density value of $1.65 \mathrm{~g} \mathrm{~cm}^{-3}$. Yet, these measurements were performed on mixes of the A and B forms. The value determined for the A form by Franklin and Gosling (1953b, 683) was $1.47 \mathrm{~g} \mathrm{~cm}^{-3}$ being equivalent to 28 nucleotides. The density for the B form could not be established. Since the interresidual spacing of the nucleotides could not be figured out for the A form Crick and Watson had to do some indirect reasoning: the A form is reduced by roughly $30 \%$, which means that the interresidual spacing is no longer 3.4 A but $2.4 \AA$. Since $28 / 2.4=2$, the A form thus contains only two and not three strands.
} 
Bragg, L., J. C. Kendrew, M. F. Perutz (1950), "Polypeptide Chain Configurations in Crystalline Proteins", Proceedings of the Royal Society of London. Series A, Mathematical and Physical Sciences, vol. 203, no. 1074, pp. 321-357.

Bragg, L. and M. F. Perutz (1952), "The external form of the haemoglobin molecule. II", Acta Crystallographia, 5, 323.

Brush, S. (1974), "Should the History of Science Be Rated X?", Science, New Series, Vol. 183, No. 4130., pp. 1164-1172.

Cartwright, N. (1999a), The dappled world: a study of the boundaries of science, Cambridge: Cambridge University Press.

Cartwright, N. (1999b), "Models and the limits of theory: quantum Hamiltonians and the BCS model of superconductivity", in: Morgan and Morrison (eds.).

Cartwright, N., M. Suarez, T. Shomar (1995), "The Tool box of Science. Tools for the Building of Models with a Superconductivity Example" in: Herfel et al. (eds.), 137149.

Cochran, W., F. Crick, V. Vand (1952), "The structure of synthetic polypeptides. I. The transform of atoms on a helix", Acta Crystallographica, vol. 5, 581.

Cochran, W. (1987), "Cochran, W., F. Crick, V. Vand (1952), The structure of synthetic polypeptides. I. The transform of atoms on a helix, Acta Crystallographica, vol. 5, 581", This Week's Citation Classic, no. 20, $18^{\text {th }}$ May.

Cracknell, A. P. (1969), Crystals and their structures, Pergamon Press LTD.: London.

Crick, F. (1952a), "The height of the vector rods in the three-dimensional Patterson of haemoglobin", Acta Crystallographica, 5, 381-386

Crick, F. (1952b), “Is $\alpha$-Keratin a Coiled Coil?”, Nature, vol. 170, n. 4334, Nov. 22, pp. 882883.

Crick, F. (1954a), “The Structure of the Hereditary Material”, Scientific American, Oct., 191(4): 54-61.

Crick, F. (1954b), "The structure of the synthetic $\alpha$ - polypeptides", Science Progress, 42, 205-219.

Crick, F. (1988), What mad pursuit: a personal view of scientific discovery, New York: Basic Books.

Crick, F. H. C. and Kendrew, J. C. (1957), "X-ray analysis and protein structure", Advances in Protein Chemistry, vol. XII, 133-214.

Crick and Watson (1953), “A Structure for Deoxyribose Nucleic Acid”, Nature, April 25, pp. 737-738.

Crick, F. H. C. and J.D. Watson (1954), "The complementary structure of Deoxyribonucleic acid", Proceedings of the Royal Society, A, 223, pp. 80-96, also in: Watson (1980).

Dickerson, R. (2005), Present at the Flood: How Structural Molecular Biology Came About, Sunderland, MA: Sinauer Associates

Donohue, J. (1978), “Fragments of Chargaff”, Nature, CCLXXVI, 5, 684, $9^{\text {th }}$ November, pp. 133-135.

Dickerson, R. and H. Drew (1981), "Kinematic Model for B-DNA", Proceedings of the National Academy of Sciences of the USA, 78, 2178-83.

Eddington, A. (1935), New Pathways in Science, Cambridge: University Press.

Fine, A. (2004), Inference to the Best Explanation, London: Routledge.

Franklin, A. (2002), Selectivity and Discord. Two Problems of Experiment, University of Pittsburgh Press, Pittsburgh.

Franklin, R. and R. Gosling (1953a), "The Structure of Sodium-Thymonucleate Fibres I. The Influence of water content", Acta Crystallographica, 6, 673pp.

Franklin and R. Gosling (1953b), "The Structure of Sodium-Thymonucleate Fibres II. The Cylindrically symmetric Patterson function”, Acta Crystallographica, 6, 678pp. 
Franklin and R. Gosling (1953c), "Molecular Configuration in Sodium Thymonucleate", Nature, 171, April 25, pp. 740-741.

French, S. and J. Ladyman (1997), 'Superconductivity and Structures: Revisiting the London Approach', Studies in History and Philosophy of Modern Physics 28 (1997), 363-93.

Frigg, R. and S. Harmann (2006), "Scientific Models", in: S. Sarkar and J. Pfeifer (eds.): The Philosophy of Science: An Encyclopedia. New York: Routledge, 740-749.

Giere, R. (2002), "How Models Are Used To Represent Physical Reality", Philosophy of Science Association (PSA), 18th Biennial Mtg., 2002, Austin, Texas.

Gruber, M. and Lupas, A. N. (2003), "Historical review: Another $50^{\text {th }}$ anniversary - new periodicities in coiled coils", Trends in Biochemical Sciences, vol. 28, no. 12, December, 679-685.

Hamilton, L. D. (1968), “DNA: Models and Reality”, Nature, vol. 218, May 18.

Holmes, K. C. and D.M. Blow (1980), The Use of X-ray diffraction in the study of protein and Nucleic Acid Structure, New York: Krieger.

Holton, G. (1978), The Scientific Imagination: case studies, Cambridge: Cambridge University Press.

Judson, H. F. (1996), The Eight Day of Creation. Makers of the Revolution in Biology, expanded edition, Cold Spring Harbor Laboratory Press.

Kendrew, J.C. and Perutz, M.F. (1949), "X-Ray Crystallography of Biological Macromolecules”, in: Kendrew J.C. and F.J.W. Roughton (1949), Haemoglobin, 161-179.

Kendrew J.C. and F.J.W. Roughton (1949) (eds.), Haemoglobin: a symposium based on a conference held at Cambridge in June 1948 in memory of Sir Joseph Barcroft, London: Butterworths Scientific Publications.

Klein, U. (2001), Tools and modes of representation in the laboratory sciences, Dordrecht: Kluwer Academic.

Klein, U. (2003), Experiments, models, paper tools : cultures of organic chemistry in the nineteenth century, Stanford, Calif.: Stanford University Press.

Klug, A. (1968), "Rosalind Franklin and the discovery of the structure of DNA", Nature, August 24, pp. 808-810, 843-844, also in Watson (1980).

Klug, A. (2004), "The discovery of the DNA double helix", in: Torsten Krude (ed.), DNA. Changing Science and Society, pp. 5-44.

Lipson, H. S. (1970), Crystals and x-rays, Wykeham Publications: London.

Maddox, Brenda (2002), Rosalind Franklin. The Dark Lady of DNA, London: HarperCollins.

Marinacci, B. (1995), Linus Pauling in His Own Words. Selections from His Writings, Speeches, and Interviews. Touchstone Books. Simon \& Schuster, New York.

Morange, M. (1998), A history of molecular biology, transl. by Matthew Cobb, Cambridge, Mass.: Harvard University Press.

Mathews, C., K. van Holde, K. Ahern (2000), Biochemistry, San Francisco: Benjamin/Cummings, 3rd ed.

Merton, R. (1968), "Making it Scientifically”, New York Times Book Review, February 25, pp. $1,41-43,45$.

Morgan, M. and M. Morrison (1999), Models as Mediators, Cambridge: Cambridge University Press.

Nye, M. J. (2001), "Paper tools and Molecular Architecture in the Chemistry of Linus Pauling", in: U. Klein (2001), pp. 117-132.

Okasha, S. (2000), "Van Fraassen's Critique of Inference to the Best Explanation", Studies in the History and the Philosophy of Science, vol. 31, no. 4, 691-710.

Olby, R. (1972). "Rosalind Elsie Franklin (1920-1958)", in: Dictionary of Scientific Biography, Vol. 5, ed. Charles Coulston Gillispie. New York: Scribner. 
Olby, R. (1994), The Path to the double helix. The discovery of DNA. Dover Publications, Inc.: New York, originally published: Seattle: University of Washington Press, 1974.

Patterson, A. L. (1934), "A Fourier Series Method for the Determination of the Components of Interatomic Distances in Crystals", Physical Review, 45, 763A.

Pauling, L., R.B. Corey, H.R. Branson (1951), "The Structure of Proteins: Two Hydrogenbonded helical configurations of the polypeptide chain", Proceedings of the National Academy of Sciences of the United States of America, vol. 37, No.4, pp. 205-211.

Pauling, L. and R. Corey (1951), "The structure of synthetic polypeptides", Proceedings of the National Academy of Sciences of the United States of America, vol. 37, no.5, 241250 .

Pauling, L. and R. Corey (1953), "Compound Helical configurations of polypeptide chains: Structure of Proteins of the $\alpha$-Keratin Type", Nature, vol. 171, no.4341, pp. 59-61.

Perutz, M.F. (1951a), "New x-ray evidence on the configuration of polypeptide chains", Nature, June 30, no. 4261, 1053-4

Perutz, M.F. (1951b), “The 1.5-A. Reflexion from Proteins and Polypeptides”, Nature, October 13, no. 4276, 653-4.

Perutz, M.F. (1963), “X-ray Analysis of Hemoglobin”, Science, May 24, vol. 140, no. 3569, 863-869.

Perutz, M. F. (1998), I wish I'd made you angry earlier. Essays on science, scientists, and humanity, Oxford: Oxford University Press.

Sayre, A. (1975), Rosalind Franklin and DNA, New York: Norton.

Schindler, S. (2006), "Imaginary-Constitutives. The Ontology of Scientific Models", presented at the Biennial Conference of Philosophy of Science Association (PSA), Vancouver, November 2006, available at http://philsci-archive.pitt.edu.

Schindler, S. (2007), "Rehabilitating Theory. The Refusal of the "bottom-up" construction of scientific phenomena", Studies in the History and the Philosophy of Science, vol. 38, 160-184.

Schindler, S. (forthcoming), "Defining the criterion of naturalness".

Suarez, M. (1999), "The role of models in the application of scientific theories: epistemological implications", M. Morgan and M. Morrison (eds.), Models as Mediators.

Suppes, P. (1960), 'A Comparison of the Meaning and Uses of Models in Mathematics and the Empirical Sciences', Synthese 12: 2/3, 287-300.

Taylor, C. A. (1967), “The Patterson function”, Physics Education, vol.2, 276-277

Van Fraassen, B. (1980), The Scientific Image, Oxford University Press

Van Holde, K., C. Johnson, S. Ho (2006), Principles of Physical Biochemistry, London: Pearson Education Ltd., $2^{\text {nd }}$ international ed.

Watson and Crick (1953), "The Structure of DNA", Cold Spring Harbor Symposia on Quantitative Biology, XVIII, pp. 123-131, also in: Watson (1980).

Watson, J.D. (1968), The double helix. A personal account of the discovery of the structure of DNA, London: Weidenfeld and Nicholson.

Watson, J.D. (1980), The double helix. A personal account of the discovery of the structure of DNA. Text, commentary, reviews, original papers, ed. G.S. Stent, C.C. Norton \& Company: New York.

Weisberg, M. (forthcoming), "Who's a modeller", to appear in the British Journal of Philosophy of Science.

Wilkins, M. (2003), The third man of the double helix: the autobiography of Maurice Wilkins, Oxford: Oxford University Press. 